\title{
Research on Quality Management System of Teaching Research Projects in the Application-oriented Undergraduate Colleges
}

\author{
Decheng Yang \\ Jilin Engineering Normal University \\ Changchun Jilin 130052
}

\begin{abstract}
In view of the problems existing in the quality manage ment of te aching rese arch subjects in application oriented universities and the lack of emphasis on process management, this paper proposes the way to do a good job in the quality management of teaching research topics, standardize the various aspects of teaching and research projects quality management, strengthen the study of the pre-project, clear the objectives of the research project, improve the transparency and guidance of the project review, strengthen the teaching and research topics from the beginning to the end of the whole process of monitoring, establish a scientific and effective management incentive mechanism, improve the school teaching and research topics management efficiency and quality to ensure the coordinated development of the quality and quantity of teaching research topics. Meantime, the application and promotion of the results of the project will be carried out to translate the results of te aching and research projects in the real sense into teaching achievements and promote the improvement of education and te aching quality.
\end{abstract}

Keywords-application-oriented undergraduate colleges; teaching and research Projects; quality management system

\section{INTRODUCTION}

At present, our country's higher education is in a new era of development. Further deepening teaching reform is an inevitable requirement for higher education to conform to the reform of the times. The strengthening of teaching research in higher universities in China is the key to deepening teaching reform and improving teaching quality. In recent years, the overall teaching and research level of application-oriented universities have been rapidly improved. Taking the research of the project as the driving force, the reform of education and teaching has shown an increasingly prosperous situation, and the number of teaching and research projects undertaken has also been increasing. However, at the same time of developing quantity, the management of the project was given insufficient attention, and there was a phenomenon of "thinking highly of the number of projects, ignoring the research quality, paying attention to the timeliness of the research, and overlooking results and application”, resulting in delays in finalization and low conversion rates and little value for project research. Therefore, improving the quality of teaching and research topics, promoting the intensification, improvement, and

Fund Project: Jilin Province Education Science "Thirteenth Five - Year Plan" Key Project: Teaching and Scientific Research of Teachers of Editing and Publishing under the Background of Application-oriented Transformation (No.: ZD17132, Presenter Yang Decheng) stage results. promotion of teaching research projects and giving full play to the role of teaching and research projects in teaching work have become issues that need to be explored in teaching management of application-oriented universities.

\section{Teaching and Research Project Quality MANAGEMENT OVERVIEW OF APPLICATION-ORIENTED UNIVERSITIES}

Teaching research is a method for revealing and recognizing the law when it is aimed at a certain problem often encountered during the teaching practice. It can form a teaching and research topic to solve problems. Based on a certain conception and purpose, it systematically controls the occurrence and development of practical phenomena in the research teaching process, and analyzes the results of the experiment to obtain substantial conclusions. The quality management of teaching and research topics is the scientific management and control process of various influencing factors of teaching and research topics. The quality management of teaching and research projects can be defined as the whole process and systematic management activities of the research of the project with the participation of all school departments and all teaching staff, with the quality of teaching and research topics as the center, and comprehensive application of modern management techniques and methods.

In recent years, with the increasing number of applicationoriented universities teaching and research topics, it is necessary to strengthen management research on teaching and research topics. Under the premise of increasing the number, it is crucial to track the whole process of topics such as topic design, application for project approval, proposal for opening a topic, mid-term examination, conclusion identification, promotion and application of topics, and social performance feedback related to project quality design. In response to the above research process, strengthening the management of application-oriented universities' teaching and research projects can ensure the quality of teaching and research topics, put the supervision of teaching and research topics into place, urge the members of the teaching and research group to complete research on the topic on time and in good quality, and immediately promote the application of research results in teaching so as to better promote teaching and improve the quality of education and teaching. 


\section{Problems in the Quality Management Process of TeAching and Research ProJects IN ApPLICATION- ORIENTED UNIVERSITIES}

Strengthening the application-oriented teaching and research project management will help improve the quality of school teaching and improve the level of school teaching management. However, from the current situation of the application-oriented universities' teaching and research topic management system, there exist some unsatisfactory points, affecting the orderly implementation of the school's teaching and research topics.

The specific performances are as follows:

\section{A. Topic selection of teaching and research with poor pertinence}

Most of the application-oriented universities have not been transformed for a long time, they have not strengthened the teaching reform management work and they have not targeted the improvement of teachers' teaching practice. The first task before the establishment of the teaching and research project is how to choose the topic according to the actual situation in the work. It is precisely this link that does not receive enough attention. For the purpose of self-evaluation of titles or completion of corresponding scientific research tasks, project applicants have made sloppy selection of topics after referring to the guidelines for project application. They did not really consider whether the research content of the project was combined with the actual teaching work, whether it was suitable for their own research ability category, and whether the composition and relevance of research team members were considered. Therefore, the following problems have emerged: Some topics are oversimplified when they are selected, lacking depth; some topics are too formalism and lack of connotation; some subjects are not qualified and declared blindly; some topics are not actually from the education and teaching practice with duplicate topics; some topics come from the Internet that people have studied better or written more. Due to the inability to grasp the perspective of the topic, their selection is not welltargeted and cannot solve the practical problems in teaching. They cannot really promote teaching through research and have little effect on the improvement of education and teaching quality.

\section{B. Lack of process management of teaching and research projects}

At present, the personnel of application-oriented universities engaged in relevant work have not upgraded from management work to business work, and have not changed from management work to service work. When publishing project information, they only played the role of forwarding documents but unable to collect, process, or even organize more information on the project. They even lacked relevant awareness and literacy in the guidance, consultation, and argumentation of the teachers' application projects. It is difficult for them to mobilize the enthusiasm and creativity of teachers' teaching and research work, and thus affect the research quality of teaching and research topics. Due to the fact that staff only proceed from the perspective of managers, lack awareness of the management of the subject process and lack extensive management experience, guidance, inspection and supervision for the opening of the report and the interim research stage, insufficient emphasis on the control of each link in the specific implementation process of the project and clear and normative and effective inspection method and system for the research progress of the project and the quality of the stage results after the project is established. In addition, most universities also attach great importance to the establishment of teaching and research projects. However, they do not pay enough attention to the process management of the project and the phenomenon of "thinking highly of the number of projects, ignoring the research quality, paying attention to the timeliness of the research, and overlooking results and application" often appears. There is no targeted and practical topic management approach, the supervision mechanism for teaching and research topics is not perfect, and a unified and comprehensive teaching and research supervision system has not been formed.

\section{Teaching and research achievements with low application rate and unsatisfying promotion effect}

As the management department of the project, only the level and quantity of the project are considered in the teaching and research topic management. No matter whether the topic is on time or not, we cannot talk about the popularization and application of teaching and research achievements with existing quantity. The reasons are as follows: some topics have no value in their own research; some studies have been unable to adapt to the needs of the development of teaching work after a period of research with the deepening of teaching reform; some teaching research results lack the means of application and the corresponding technical conditions; some topics can no longer be studied because of changes in the work of the project leader; and some subjects, because of the lack of ways and means of propaganda by the competent departments just talk about stratagems on paper and have no practical significance for teaching work.

\section{Teaching and Research Project Quality MANAGEMENT SYSTEM OF APPLICATION-ORIENTED UNIVERSITIES}

Teaching is the center of all kinds of school work. Teaching quality is the lifeline of school education. In-depth and extensive teaching research is an effective means to improve the quality of education and teaching. Only by scientifically constructing a teaching research project quality management system and operating mechanism (see Figure 1), and earnestly emphasizing and strengthening the quality management of teaching research projects can we achieve research objectives, ensure research quality, and cultivate high-quality teaching results. 


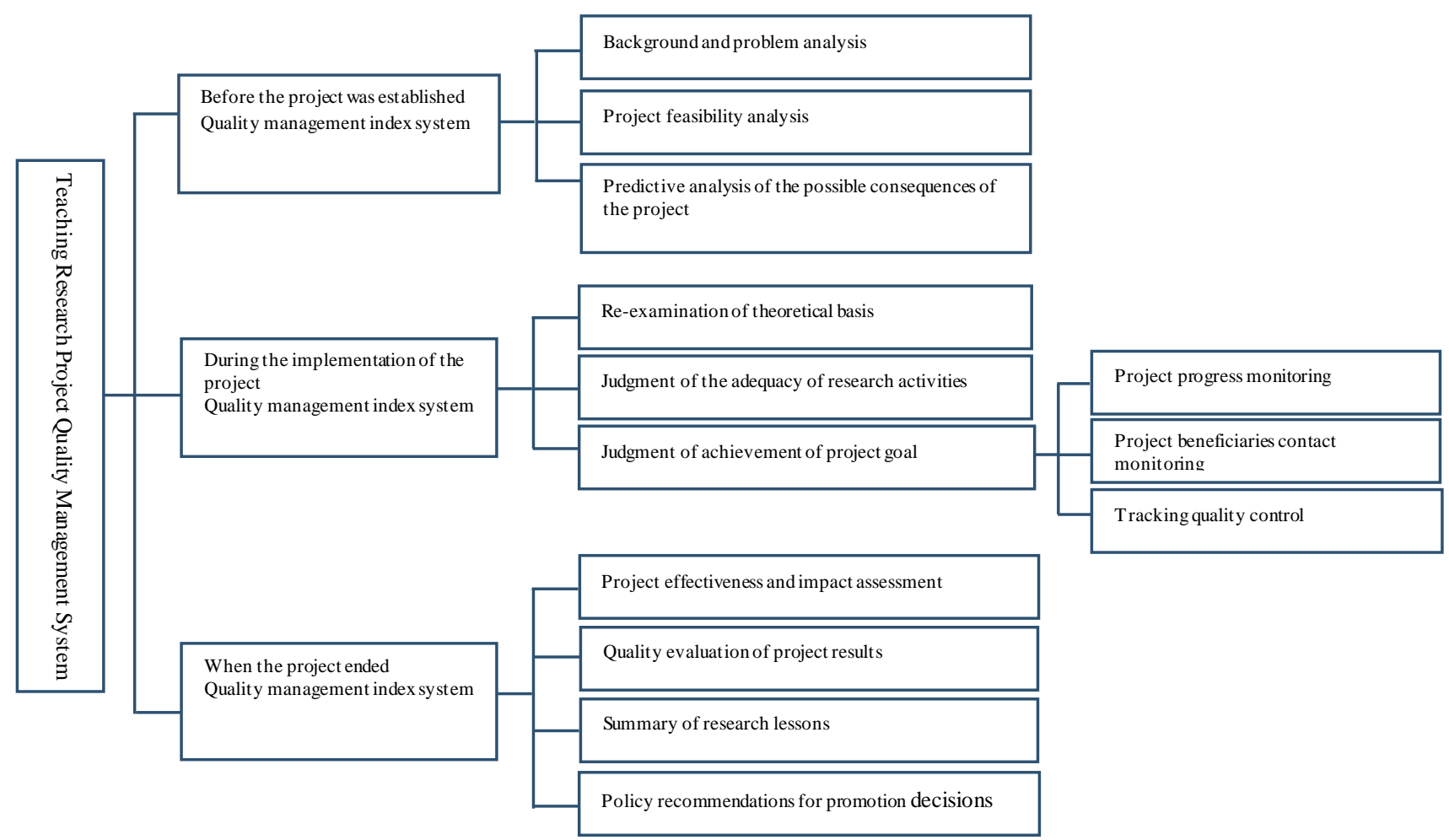

Fig. 1. Teaching research project quality management system and operating mechanism

\section{A. Pay attention to project evaluation work}

The teaching and research project should adopt the method of tendering major projects and combining teachers' self-selected topics according to their own advantages. Before the project is established, the project management department shall, in accordance with the spirit of higher education reform and the current demand for talents from local economic construction, formulate important projects affecting teaching quality in such areas as teaching reform, teaching construction, and teaching management as the subject of tendering, constitute specific goals to be achieved for each topic and issue guidelines for issues. All units should select topics according to the actual situation, organize their forces to do a good job of preliminary investigations, clarify the requirements and directions for project declarations, analyze the project's project background, feasibility of implementation, propose solutions to existing problems, and carefully design and write an argument report. Meantime, all units should strictly implement the evaluation criteria of the project, give full play to the role of the evaluation experts, reflect the innovative points of the project, highlight the value of practical application, answer expert questions, and better complete the supervision mechanism for project evaluation through the defense.

\section{B. Strengthen the process of project management}

Process management refers to the supervision, inspection and feedback adjustment of the whole process of the research of the project to ensure that the project is implemented according to the objectives of the project and achieve the desired results. Strengthening the process management of teaching and research topics is the prerequisite for improving the quality of teaching and research topics and ensuring the smooth development of teaching and research topics. To use the rolling contract system to manage teaching research projects, the project leader and the relevant departments shall sign the contract, and according to the progress of the project, the expert team shall conduct timely supervision and inspection. Phase inspection is the key to ensure the success of teaching research projects. During the implementation of the project, the university shall regularly or irregularly organize experts to supervise the research projects of each unit, check the progress of each project according to the research plan, the phased results obtained, the innovations, etc., grasp the progress of the project, encourage the achievement of the achievement of the stage, and warn or revoke the problem of ineffective conduct of the violation or research work. When the project is completed, the project unit should organize an expert group to conduct the appraisal. Experts not only need to assess the theoretical basis of the results, the level of achievements, the effectiveness of the practice, the value of promotion, etc., but also should go deep into the field to conduct a fair and objective evaluation of the teaching achievements that have been achieved.

\section{Attach importance to the achievement of the project transformation}

The promotion and application of teaching and research results is an important part of teaching research and management. With this link, teaching and research can truly promote the teaching work to a higher level. The teaching 
results are formed on the basis of research and after a long period of practice. Its practical objects are students, and its effect is also embodied by students. Application-oriented universe should work hard to build a promotion platform for results, increase the integration of universities and enterprises, provide first-line teachers with a broader practice, and train new-age "dual-qualified" teachers. At the same time, as a project management department, universities should apply for teaching results in strict accordance with the relevant requirements of the higher authorities, strive to improve the school's award system for teaching achievements, increase the establishment of awards, cultivate practically valuable project results in advance, and encourage more project research results to declare teaching results. Teaching is a continuous process of practice. Teaching results are all staged. In the dissemination of results, universities should make full use of the Internet, newspapers, publicity films and other forms of media to publicize and promote the results achieved. Besides, they can also take the form of holding report meetings, academic exchanges, and other forms, display and promote results in the form of papers and compilations of results so that they can exert more obvious practical effects. In the end, the purpose of using teaching reform as a driving force, teaching and research as a means, attaching importance to the good atmosphere of teaching, and serving as a leading role in other projects can be achieved to realize the transformation of results of the teaching and research project into teaching achievements and promote the improvement of education and teaching quality.

\section{REFERENCES}

[1] Li Fuzheng. Strengthen Management of Teaching Research Achievements and Improve Teaching Quality [J]. Higher Education Research, 2001.

[2] Pang Lan, Ouyang Jianping. Several Thoughts on Strengthening the Management of Teaching Research Projects in Universities [J]. Chinese Geological Education, 2002.

[3] Lu Jifeng, Chen Bingxia. Construction of Management System and Operation Mechanism for Teaching Research Projects in Universities [J]. China Electric Power Education, 2010.

[4] Chang Hongjian, Zhang Tiqin. Research on Innovation of Scientific Research Project Management Model in Colleges and Universities.[J].Technology and Innovation Management,2010(7):412415.

[5] Chen Mengran. How Young Teachers in Colleges and Universities Get Out of the Mistakes in Teaching Research Projects[J]. Higher Education Management, 2011.

[6] Hou Xinying. How to Carry out Research Projects in Depth[J]. New Course (Secondary), 2015. 